\title{
Caboxamycin, a new antibiotic of the benzoxazole family produced by the deep-sea strain Streptomyces sp. NTK $937^{*}$
}

\author{
Claudia Hohmann ${ }^{1,8}$, Kathrin Schneider ${ }^{2,8}$, Christina Bruntner ${ }^{1}$, Elisabeth Irran $^{2}$, Graeme Nicholson ${ }^{3}$, \\ Alan T Bull ${ }^{4}$, Amanda L Jones ${ }^{5}$, Roselyn Brown ${ }^{5}$, James EM Stach ${ }^{5}$, Michael Goodfellow ${ }^{5}$, Winfried Beil ${ }^{6}$, \\ Marco Krämer ${ }^{7}$, Johannes F Imhoff ${ }^{7}$, Roderich D Süssmuth ${ }^{2}$ and Hans-Peter Fiedler ${ }^{1}$ \\ Caboxamycin, a new benzoxazole antibiotic, was detected by HPLC-diode array screening in extracts of the marine strain \\ Streptomyces sp. NTK 937, which was isolated from deep-sea sediment collected in the Canary Basin. The structure of \\ caboxamycin was determined by mass spectrometry, NMR experiments and X-ray analysis. It showed inhibitory activity against \\ Gram-positive bacteria, selected human tumor cell lines and the enzyme phosphodiesterase.
}

The Journal of Antibiotics (2009) 62, 99-104; doi:10.1038/ja.2008.24; published online 23 January 2009

Keywords: benzoxazole antibiotic; fermentation; isolation; marine Streptomyces; structural elucidation

\section{INTRODUCTION}

A set of 600 actinomycetes isolated from marine sediments from various sites in the Atlantic and Pacific Oceans were screened using our HPLCdiode array technology for the production of bioactive secondary metabolites. It is becoming increasingly clear that actinomycetes isolated from marine habitats are a rich source of new natural products, including drug candidates. ${ }^{1-5}$ Extracts from the culture filtrate of strain NTK 937 showed a prominent peak in the HPLC-diode array analysis that had an unusual UV-visible spectrum, albeit it was similar to that of nataxazole from our HPLC-UV-Vis database which contains 867 entries, mostly antibiotics. ${ }^{6}$ Nataxazole, a new member of the benzoxazole family of antibiotics, was extracted from terrestrial Streptomyces sp. Tü $6176 .^{7}$ Nataxazole has a structure similar to that of benzoxazoles UK- $1^{8}$ and AJI9561, ${ }^{9}$ which were derived from Streptomyces strains, and were shown to have potent anti-tumor properties. The similarity of the UV-visible spectrum of the metabolite produced by strain NTK 937 to nataxazole underlines its structural relationship to benzoxazoles; the new compound was named caboxamycin (1) composed from the strain's collection site, the Canary Basin and the benzoxazole scaffold of its structure, which is shown in Figure 1. Herein, we report on the taxonomy of the producing strain, the fermentation, isolation and structural elucidation of caboxamycin and its biological activities.

\section{RESULTS}

Taxonomy of the producing strain

The chemical and morphological properties of strain NTK 937 were consistent with its classification in the genus Streptomyces. ${ }^{10}$ The organism formed an extensively branched substrate mycelium, straight spore chains on the aerial mycelium, contained hexa- and octahydrogenated menaquinones with nine isoprene units as the predominate isoprenologues, and gave whole-cell hydrolysates rich in LL-diaminopimelic acid. Comparison of an almost complete 16S rRNA sequence of strain NTK 937 with corresponding sequences of Streptomyces type strains showed that it formed a distinct phyletic line in the Streptomyces 16S rRNA gene tree.

Screening, fermentation and isolation

When grown in the 20-liter fermentor strain NTK 937 reached a maximal biomass of $12 \mathrm{mg}$ dry weight per $\mathrm{ml}$ after 5 days of incubation. Production of 1 started at $72 \mathrm{~h}$, reaching a maximal yield of $15 \mathrm{mgl}^{-1}$ after incubation for 5 days. The HPLC elution profile of the corresponding culture filtrate is shown in Figure 2. 1 was isolated from the culture filtrate by separation on an Amberlite XAD16 column; the extracts were concentrated to an aqueous residue and extracted with ethylacetate and concentrated in vacuo to dryness. The

${ }^{1}$ Mikrobiologisches Institut, Universität Tübingen, Auf der Morgenstelle, Tübingen, Germany; ${ }^{2}$ Institut für Chemie, Technische Universität Berlin, Berlin, Germany; ${ }^{3}$ Institut für Organische Chemie, Universität Tübingen, Auf der Morgenstelle, Tübingen, Germany; ${ }^{4}$ Research School of Biosciences, University of Kent, Canterbury, UK; ${ }^{5}$ School of Biology, Newcastle University, Newcastle upon Tyne, UK; ${ }^{9}$ nnstitut für Pharmakologie, Medizinische Hochschule Hannover, Carl-Neuberg-Str. 1, Hannover, Germany and ${ }^{7}$ Leibniz-Institut für Meereswissenschaften IFM-GEOMAR, Düsternbrooker, Kiel, Germany

${ }^{8}$ These authors contributed equally to this work.

Correspondence: Dr RD Süssmuth, Institut für Chemie, Technische Universität Berlin, Straße des 17. Juni 124, 10623 Berlin, Germany.

E-mail: suessmuth@chem.tu-berlin.de or H-P Fiedler, Mikrobiologisches Institut, Universität Tübingen, Auf der Morgenstelle 28, 72076 Tübingen, Germany.

E-mail: hans-peter.fiedler@uni-tuebingen.de

*Art. No. 48 in 'Biosynthetic Capacities of Actinomycetes'. Art. No. 47: See ref. 7

Received 25 July 2008; accepted 17 December 2008; published online 23 January 2009 




Figure 1 Structure of caboxamycin (1).

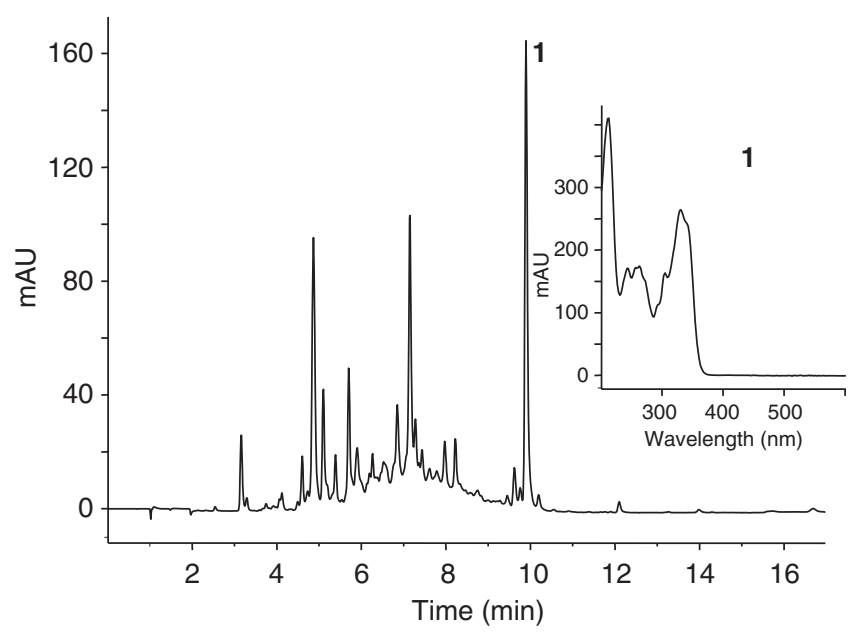

Figure 2 HPLC analysis of a culture filtrate from Streptomyces sp. NTK 937 at a fermentation time of $120 \mathrm{~h}$, monitored at $310 \mathrm{~nm}$, and UV-visible spectrum of caboxamycin (1), retention time $9.9 \mathrm{~min}$.

crude product was purified by chromatography on a diol-modified silica gel column followed by chromatography on a Sephadex LH-20 and Toyopearl HW-40S column. 1 was obtained as a white, yellowfluorescent powder after concentrated to dryness.

\section{Structural elucidation}

The mass spectrum derived from the HPLC-ESI-MS chromatograms revealed the molecular mass for $1\left[(\mathrm{M}+\mathrm{H})^{+}=256.0\right]$. The exact molecular mass was determined by high-resolution ESI-FT-ICR-MS as $256.06010 \mathrm{Da}\left[(\mathrm{M}+\mathrm{H})^{+}\right](\mathbf{1})$, this corresponds to the molecular formulae $\mathrm{C}_{14} \mathrm{H}_{9} \mathrm{NO}_{4}(1)\left[(\mathrm{M}+\mathrm{H})^{+}{ }_{\text {theor }}=256.06043 ; \Delta \mathrm{m}=1.29\right.$ p.p.m. $]$. The ESI-FTICR-MS measurement of 1 showed an additional molecular mass of $564.02409 \mathrm{Da}\left[(\mathrm{M}-3 \mathrm{H}+\mathrm{Fe}+\mathrm{H})^{+}\right]$. This corresponds well with the molecular formula $\mathrm{C}_{28} \mathrm{H}_{16} \mathrm{~N}_{2} \mathrm{O}_{8} \mathrm{Fe}\left[(2 \mathrm{M}-3 \mathrm{H}+\mathrm{Fe}+\mathrm{H})^{+}\right.$theor $=564.02506 ; \Delta \mathrm{m}=1.72$ p.p.m.] and suggests that the compound is able to complex metal ions. The physico-chemical properties of $\mathbf{1}$ are summarized in Table 1.

The ${ }^{1} \mathrm{H}-\mathrm{NMR}$-spectrum of $\mathbf{1}$ showed seven signals in the aromatic region between 8.2 and 7 p.p.m. and one broad signal at 11.8 p.p.m. ${ }^{13} \mathrm{C}-\mathrm{NMR}$ and DEPT spectra revealed the presence of seven aromatic $\mathrm{CH}$ groups and seven quaternary carbons between 170 and 110 p.p.m. The correlation of ${ }^{1} \mathrm{H}$-NMR-signals to the corresponding C-atoms was determined in a Heteronuclear Multiple Quantum Coherence NMR experiment. Seven signals were found in accordance with the DEPT spectrum. Compared to the molecular formula, $\mathrm{C}_{14} \mathrm{H}_{9} \mathrm{~N}_{1} \mathrm{O}_{4}$, two protons should be bound to heteroatoms $(\mathrm{OH}$ or $\mathrm{NH}$ ), one of which giving a broad signal at 11.8 p.p.m. in the ${ }^{1} \mathrm{H}-\mathrm{NMR}-$ spectrum.
Table 1 Physico-chemical properties of caboxamycin (1)

\begin{tabular}{ll}
\hline & $\mathbf{1}$ \\
\hline $\begin{array}{l}\text { Appearance } \\
\text { Molecular weight }\end{array}$ & White powder \\
$\begin{array}{l}\text { Molecular formula } \\
\text { ESI-FT-ICR MS }\left(\mathrm{mz}^{-1}\right)\end{array}$ & $\mathrm{C}_{14} \mathrm{H}_{9} \mathrm{~N}_{1} \mathrm{O}_{4}$ \\
$\quad$ & \\
$\quad$ Found & $256.06010(\mathrm{M}+\mathrm{H})^{+}$ \\
$\quad$ Calcd & $256.06043(\mathrm{M}+\mathrm{H})^{+}$ \\
UV $\lambda_{\max }^{\mathrm{M} O \mathrm{H}}[\mathrm{nm}]$ & \\
$\left(\varepsilon\left[\mathrm{cm}^{2} \mathrm{mmol}^{-1}\right]\right)$ & $212(20), 243(8.16), 257(\mathrm{sh}, 8.16), 263(8.37)$, \\
& $273(\mathrm{sh}, 7.35), 292(\mathrm{sh}, 5.51), 305(\mathrm{sh}, 7.76)$, \\
& $331(11.43), 342(\mathrm{sh}, 10.82)$ \\
IR $v_{\max }\left(\mathrm{cm}^{-1}\right)$ & $3466,3088,3046,3006,2956,2920,2850$, \\
& $2676,2570,1690,1633,1591,1546,1486$, \\
& $1433,1296,1264,1247,1239,1183,1155$, \\
& $1065,875,752,740,724$ \\
\hline
\end{tabular}

The structure was fully elucidated using COSY and HMBC spectra. The ${ }^{1} \mathrm{H}-{ }^{1} \mathrm{H}$-COSY experiment revealed two spin systems, one of which showed correlations from $\mathrm{H}-4$ to $\mathrm{H}-6$ and the other one from $\mathrm{H}-10$ to $\mathrm{H}-13$ (Figure 3). The structure was fully elucidated using the HMBC spectrum; structure consists of two constituents, a salicylic acid and a hydroxy-anthranilic acid connected by a ring closure between the carboxylic acid group of the salicylic acid and the hydroxyl- and amingroups of the hydroxy-anthranilic acid (Figure 1). The correlations from $\mathrm{H}-5^{\prime}$ to $\mathrm{C}-2^{\prime \prime}, \mathrm{C}-3^{\prime}$ a and $\mathrm{C}-7^{\prime}$, from $\mathrm{H}-6^{\prime}$ to C-4' and C-7'a and from $\mathrm{H}-7^{\prime}$ to $\mathrm{C}-3^{\prime} \mathrm{a}$ and $\mathrm{C}-5^{\prime}$, shown in Figure 3, together with the chemical shifts of C-3'a, 138.7 p.p.m. and C-7'a, 149.5 p.p.m., prove the presence of a hydroxy-anthranilic acid, especially for the positions of the nitrogen-, the oxygen-atoms and of the carboxylic acid group at $\mathrm{C}-3^{\prime}$ a. The presence of a salicylic acid moiety was proven by the connectivities from $\mathrm{H}-3$ to $\mathrm{C}-1$ and $\mathrm{C}-5$, from $\mathrm{H}-4$ to $\mathrm{C}-2$ and $\mathrm{C}-6$, from $\mathrm{H}-5$ to $\mathrm{C}-1$ and $\mathrm{C}-3$ and from $\mathrm{H}-6$ to $\mathrm{C}-2^{\prime}, \mathrm{C}-2$ and $\mathrm{C}-4$ (Figure 3). Comparing the NMR data obtained for 1 , summarized in Table 2, to the NMR data of known metabolites (Table 2) with a similar structure; for example, AJI9561 ${ }^{11}$ (Figure 4), verifies the structure of 1. Moreover, parallel to NMR studies, crystallization experiments were performed with a single crystal obtained for compound 1. Subsequent X-ray structural determination fully confirmed the structure of compound 1 (Figure 3).

\section{Biological activity}

Caboxamycin (1) showed antibiotic activity against the Gram-positive bacteria Bacillus subtilis $\left(\mathrm{IC}_{50}=8 \mu \mathrm{M}\right)$, Staphylococcus lentus $\left(\mathrm{IC}_{50}=20 \mu \mathrm{M}\right)$ and the yeast Candida glabrata $\left(\mathrm{IC}_{50}=117 \mu \mathrm{M}\right)$. Also the biofilm formation of Staphylococcus xylosus was weakly inhibited. A significant activity was present against the phytopathogenic bacteria Xanthomonas campestris $\left(\mathrm{IC}_{50}=43 \mu \mathrm{M}\right)$ and Ralstonia solanacearum $\left(\mathrm{IC}_{50}=176 \mu \mathrm{M}\right)$ and against the opportunistic pathogen Staphylococcus epidermidis $\left(\mathrm{IC}_{50}=43 \mu \mathrm{M}\right.$ ). The corresponding data for chloramphenicol (positive control prokaryotes) were: Bacillus subtilis $\left(\mathrm{IC}_{50}=9 \mu \mathrm{M}\right)$, Staphylococcus lentus $\left(\mathrm{IC}_{50}=14 \mu \mathrm{M}\right)$, Xanthomonas campestris $\left(\mathrm{IC}_{50}=6 \mu \mathrm{M}\right)$, Ralstonia solanacearum $\left(\mathrm{IC}_{50}=75 \mu \mathrm{M}\right)$, Staphylococcus epidermidis $\left(\mathrm{IC}_{50}=7 \mu \mathrm{M}\right)$ and for cycloheximide (positive control eukaryotes): Candida glabrata $\left(\mathrm{IC}_{50}=4 \mu \mathrm{M}\right)$.

The cytotoxic effect of caboxamycin (1) was tested in different tumor cell lines. It showed a moderate growth inhibitory activity $\left(\mathrm{IC}_{50}\right.$ : 28.6-29.4 $\left.\mu \mathrm{M}\right)$ towards gastric adenocarcinoma (AGS), hepato- 
a

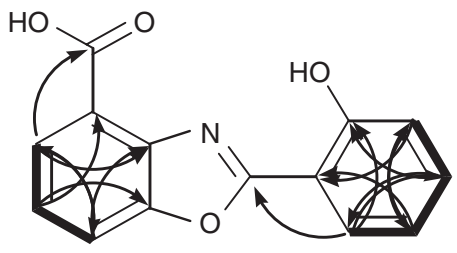

$\longrightarrow{ }^{1} \mathrm{H}-{ }^{-1} \mathrm{H}$ COSY b

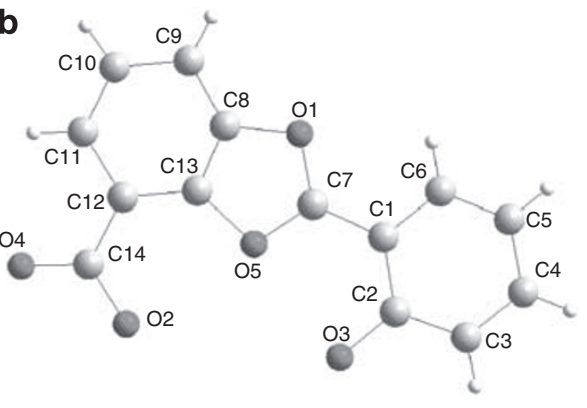

Figure 3 Selected 2D NMR correlations (a) and X-ray structure (b) of caboxamycin (1).

Table $2{ }^{1} \mathrm{H}$ and ${ }^{13} \mathrm{C}$ NMR spectral data of caboxamycin (1) and AJI9561 (3) ${ }^{11}$ in DMSO- $d_{6}$

\begin{tabular}{|c|c|c|c|c|}
\hline \multirow[b]{2}{*}{ No. } & \multicolumn{2}{|c|}{1 in $\mathrm{DMSO}^{-d_{6}}$} & \multicolumn{2}{|c|}{3 in DMSO-d $d_{6}$} \\
\hline & $\begin{array}{c}\delta\left({ }^{1} H\right) \text { [p.p.m.] } \\
J \text { in } \mathrm{Hz}\end{array}$ & $\begin{array}{l}\delta\left({ }^{13} \mathrm{C}\right) \\
{[\text { p.p.m.] }}\end{array}$ & $\begin{array}{c}\delta\left({ }^{1} H\right) \text { [p.p.m.] } \\
J \text { in } \mathrm{Hz}\end{array}$ & $\begin{array}{l}\delta\left({ }^{13} \mathrm{C}\right) \\
\text { [p.p.m.] }\end{array}$ \\
\hline 1 & & 109.7 & - & 120.5 \\
\hline 2 & & 158.4 & - & 150.4 \\
\hline 3 & $7.12 \mathrm{~d}(8.13)$ & 117.3 & $7.06 \mathrm{~d}(8.0)$ & 121.1 \\
\hline 4 & $7.53 \mathrm{~m}$ & 134.4 & 7.36 t (8.0) & 131.8 \\
\hline 5 & 7.07 t (7.23) & 119.9 & $6.85 \mathrm{~d}(8.0)$ & 128.7 \\
\hline 6 & $8.00 \mathrm{~d}(7.61)$ & 127.4 & & 140.8 \\
\hline $2^{\prime}$ & & 163.6 & & 161.5 \\
\hline 3'a & & 138.7 & & 139.9 \\
\hline $4^{\prime}$ & & 121.8 & & 118.7 \\
\hline $5^{\prime}$ & $7.97 \mathrm{~d}(7.74)$ & 127.2 & $8.37 \mathrm{~d}(7.6)$ & 125.9 \\
\hline $6^{\prime}$ & $7.54 \mathrm{~m}$ & 125.3 & 7.59 t (7.6) & 125.3 \\
\hline $7^{\prime}$ & $8.07 \mathrm{~d}(8.00)$ & 115.3 & $7.88 \mathrm{~d}(7.6)$ & 113.9 \\
\hline 7 'a & & 149.5 & & 151.2 \\
\hline $2^{\prime \prime}$ & & 165.6 & & 162.8 \\
\hline $3^{\prime \prime} a$ & & & & 141.4 \\
\hline $4^{\prime \prime}$ & & & & 122.3 \\
\hline $5^{\prime \prime}$ & & & $8.21 \mathrm{~d}(8.0)$ & 127.3 \\
\hline 6" & & & $7.58 \mathrm{~d}(8.0)$ & 124.8 \\
\hline $7^{\prime \prime}$ & & & 7.94 d (8.0) & 115.3 \\
\hline $7 " \mathrm{a}$ & & & & 151.7 \\
\hline $\mathrm{Me}$ & & & $2.86 \mathrm{~s}$ & 21.3 \\
\hline $\mathrm{OH}$ & & & $12.91 \mathrm{brs}$ & \\
\hline $\mathrm{COOH}$ & & & $11.7 \mathrm{br}$ & \\
\hline
\end{tabular}

cellular carcinoma (Hep G2) and breast carcinoma cells (MCF7). UK-1 (2) was more potent than 1 (Table 3).

Caboxamycin (1) is a weak inhibitor of bovine brain PDE $\left(\mathrm{IC}_{50}=148 \mu \mathrm{M}\right)$ and only slightly inhibited human PDE-4B2 $\left(\mathrm{IC}_{50}=1.46 \mathrm{~mm}\right)$.

\section{DISCUSSION}

The benzoxazole core structure of caboxamycin (1) is part of the natural products UK-1 (2) from Streptomyces sp. 517-02, ${ }^{8}$ AJI9561 (3) from Streptomyces sp. AJI9561 ${ }^{9}$ and nataxazole (4) from Streptomyces sp. Tü $6176 .{ }^{7} 2 \sim 4$ showed potent cytotoxic activities against various tumor cell lines whereas growth inhibition was not observed against Gram-positive or Gram-negative bacteria, or against yeasts and fungi. Furthermore, two derivatives of UK-1, Me-UK-1 (5) and DeMe-UK-1

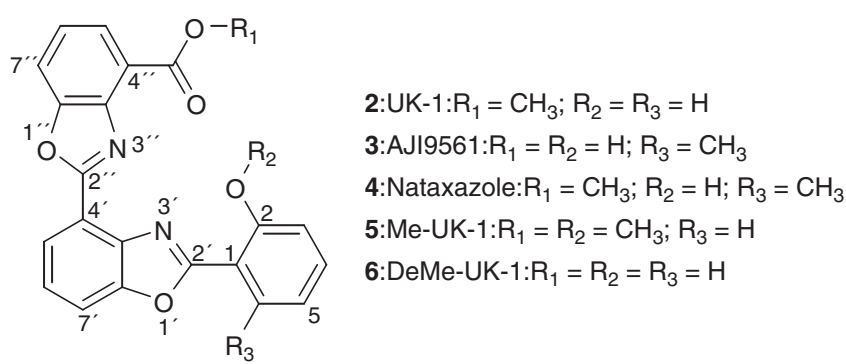

Figure 4 Structures of benzoxazole metabolites from Streptomyces strains.

Table 3 Growth inhibitory activity ( $\mu \mathrm{g} \mathrm{ml}^{-1}$ ) of caboxamycin (1) and UK-1 (2) against selected human tumor cell lines

\begin{tabular}{|c|c|c|c|c|}
\hline \multirow{2}{*}{ Cell line } & \multicolumn{2}{|c|}{1} & \multicolumn{2}{|c|}{2} \\
\hline & $\mathrm{Gl}_{50}$ & $T G I$ & $\mathrm{Gl}_{50}$ & $T G I$ \\
\hline AGS & 7.5 & $>10^{a}$ & 0.8 & 1.9 \\
\hline Hep G2 & 7.4 & $>10^{b}$ & 0.085 & 2.4 \\
\hline MCF7 & 7.3 & $>10^{c}$ & 0.65 & 3.5 \\
\hline
\end{tabular}

Abbreviations: $\mathrm{Gl}_{50}, 50 \%$ growth inhibition; TGI, $100 \%$ growth inhibition.

a72\% inhibition at $10 \mu \mathrm{g} \mathrm{ml}^{-1}$

b70\% inhibition at $10 \mu \mathrm{g} \mathrm{ml}-1$.

${ }^{\mathrm{c}} 80 \%$ inhibition at $10 \mu \mathrm{g} \mathrm{m}^{-1}$.

(6), were prepared by methylation with methyl iodide and alkaline hydrolysis, respectively; ${ }^{12}$ their structures are shown in Figure 4. Interestingly, $\mathbf{6}$ exhibited anti-bacterial activity ${ }^{13}$ and $\mathbf{5}$ anti-fungal activity. $^{14}$

In the last decade efforts have been made to understand the selective cytotoxic activity of UK-1 (2) towards cancer cells versus bacteria and fungi, and for this purpose various synthetic derivates have been prepared (Figure 5) and their biological activities evaluated and compared. ${ }^{15-17}$ Reynolds et al. ${ }^{18}$ investigated the metal ion coordination by 2 . It was shown that 2 bound divalent metal ions and DNA in a divalent metal ion-dependent manner. It also bound to doublestranded DNA 10 times more tightly in the presence of $\mathrm{Mg}^{2+}$ and inhibited human topoisomerase II. ${ }^{16}$

It was demonstrated that the synthetic benzoxazole derivative 7 , which is the methyl ester of $\mathbf{1}$, retained the selectivity of the natural product against cancer cells and therefore represents a minimum structural pharmacophore. ${ }^{14}$ The synthetic derivative $\mathbf{8}$, which constitutes the methyl ether of $\mathbf{1}$ and $\mathbf{9}$, which represents the decarboxylated 1, did not exhibit any cytotoxic or anti-bacterial activities. ${ }^{15}$ It 


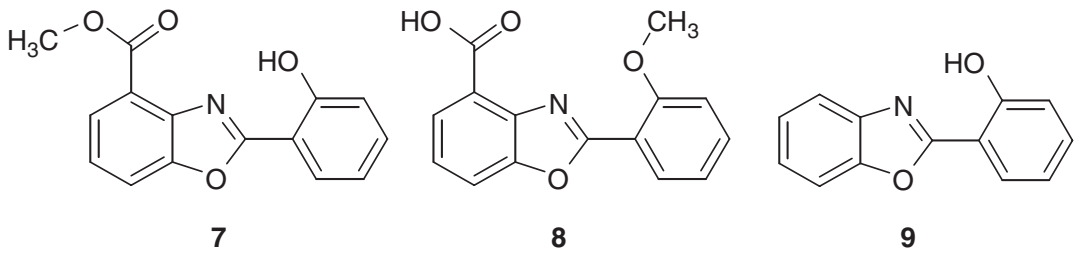

Figure 5 Structures of synthetic benzoxazole derivatives. ${ }^{14}$<smiles>O=C(Nc1c(O)cccc1-c1nc2c(C(=O)O)cccc2o1)c1ncccc1O</smiles>

10

Figure 6 Structure of antibiotic A33853.

was shown that an appropriate substituent in position $4^{\prime}$ of the benzoxazole core is important for an efficient $\mathrm{Mg}^{2+}$-binding ability. The described cytotoxic activity of the described natural product $\mathbf{1}$ and the observation of an iron-intermediate with ESI-FT-ICR-MS are in accordance with these results. UK-1 displays cytotoxic activity against certain solid tumor-derived cell lines. ${ }^{15}$ Caboxamycin is less potent than UK-1. Therefore the interaction between 2 and the $\mathrm{Mg}^{2+}$ ion may be stronger than that of $\mathbf{1}$. Synthetic derived $\mathbf{1}$ has been described as an intermediate in the synthesis of benzoxazole carboxamides, but its biological activity has not been evaluated. ${ }^{19}$ The streptomycete metabolite 1 and the evaluation of its biological activity add an element to the investigations of synthetic derivatives of the natural product UK-1 (2).

A further benzoxazole natural product related to UK-1 family is antibiotic A-33853 (10) which is produced by a Streptomyces strain; ${ }^{20}$ its structure is shown in Figure 6. Although benzoxazoles 2-6 are composed of two molecules, hydroxy-anthranilic acid and one salicylic acid, which form two ring closures resulting in the bis(benzoxazole) structure, $\mathbf{1 0}$ consists of two molecules, hydroxy-anthranilic acid and one 3-hydroxy-picolinic acid, which build one benzoxazole and one amide bond. Interestingly, 10 showed anti-bacterial activity against penicillin-resistant Staphylococcus and Streptococcus strains, and antiviral and anti-trichomonal activities in vitro. ${ }^{20}$ Unfortunately, data are not available on the cytotoxic activity and the metal-binding ability of $\mathbf{1 0}$, hence it is not possible to consider the contributions of the various structural elements to the biological activity.

Among biological activities of caboxamycin (1) the inhibition of phosphodiesterases are notable. Phosphodiesterases are essential regulators of cyclic nucleotide signalling with diverse physiological functions. PDE-4-selective inhibitors have therapeutic potential for treating major diseases, such as asthmatic inflammation and chronic obstructive pulmonary disease ${ }^{21,22}$ and several PDE-4 inhibitors have reached the clinical trial of phases II and III status. ${ }^{22}$ The PDE-4B enzyme is widely expressed in human inflammatory cells, negatively regulates a wide range of pro-inflammatory and immune cells ${ }^{21,23}$ and appears to be involved in the production of the tumor necrosis factor
TNF- $\alpha$ and other cytokines promoting the inflammatory response. ${ }^{22}$ Therefore, by inhibiting the PDE- $4 \mathrm{~B}$ enzyme, inflammatory response is blocked or strongly reduced.

The results pointed out, that caboxamycin has a 10 -fold stronger inhibitory effect to the mixture of the three bovine PDE isoforms $\left(\mathrm{IC}_{50}=148 \mu \mathrm{M}\right)$ than on the human PDE-4B2 $\left(\mathrm{IC}_{50}=1.46 \mathrm{~mm}\right)$. This might be based on significantly stronger inhibition of PDE-2 and PDE- 10 by caboxamycin than PDE-4. Despite this weak inhibition, the effect is notable because the effect against other phosphodiesterases possibly may be much stronger than the measured effects against the selection of enzymes tested. In addition, structural modifications of the caboxamycin molecule may yield molecules demonstrating much stronger effects. Structural modification according to the binding properties to human PDE-4B2 already has successfully been carried out with other PDE-4 inhibitors. ${ }^{22}$

\section{METHODS}

\section{Producing organism and taxonomy}

Strain NTK 937 was isolated from an Atlantic Ocean deep-sea sediment core collected in 2001 at the southern edge of the Saharan debris flow near the Canary Islands $\left(27^{\circ} 02^{\prime} 392 \mathrm{~N}, 18^{\circ} 29^{\prime} 022 \mathrm{~W}\right)$ at a depth of $3814 \mathrm{~m}$. Isolations were made from the turbidite fraction of the core $(0-38 \mathrm{~cm}$ from surface) which was deposited approximately 1,000 years ago, but derived from older (approximately 200000 years) previously deposited sediment from further upslope. $^{11}$

Strain NTK 937 was examined using a combination of genotypic and phenotypic procedures known to produce data of value in the delineation of Streptomyces species..$^{24,25}$

\section{Fermentation and isolation}

Batch fermentations of strain NTK 937 were carried out in a 20-liter fermentor equipped with a turbine impeller system (b20; B.Braun, Melsungen, Germany) in a complex medium consisting of mannitol $20 \mathrm{~g}$ and soybean meal $20 \mathrm{~g}$ in 11 tap water; $\mathrm{pH}$ was adjusted to 7.5 prior to sterilization. The fermentor was inoculated with $5 \%$ by volume of a shake flask culture grown in a seed medium at $27^{\circ} \mathrm{C}$ in $500 \mathrm{ml}$-Erlenmeyer flasks with a single baffle for $72 \mathrm{~h}$ on a rotary shaker at 120 r.p.m. The fermentation was carried out for 5 days with an aeration rate of 0.5 -volume air/volume/minute and agitation at 250 r.p.m.

Hyphlo Super-cel $(2 \%)$ was added to the fermentation broth, which was separated by multiple sheet filtration into culture filtrate and mycelium. The culture filtrate was applied to an Amberlite XAD-16 column (resin volume $800 \mathrm{ml}$ ) and the resin washed with $\mathrm{H}_{2} \mathrm{O}$ and $\mathrm{H}_{2} \mathrm{O}-\mathrm{MeOH}$ (8:2); caboxamycin (1) was eluted with $100 \% \mathrm{MeOH}$ and concentrated in vacuo to an aqueous residue. The concentrate was extracted three times with ethylacetate, and the organic extracts combined and concentrated in vacuo to dryness. The crude product was dissolved in $\mathrm{MeOH}$ and applied to a diol-modified silica gel column $(40 \times 2.5 \mathrm{~cm}$; LiChroprep Diol, Merck, Darmstadt, Germany). 1 was separated using a linear gradient of cyclohexane-DCM-MeOH and was eluted with $\mathrm{DCM}-10 \% \mathrm{MeOH}$ at a flow rate of $420 \mathrm{ml} \mathrm{h}^{-1}$. Further purification was achieved by chromatography on Sephadex LH-20 using MeOH-DCM (2:1) and Toyopearl $\mathrm{HW}-40 \mathrm{~S}$ with $\mathrm{MeOH}$ (each column $90 \times 2.5 \mathrm{~cm}$ ) at a flow rate of $30 \mathrm{mlh}^{-1}$. 


\section{HPLC-DAD analyses}

The chromatographic system consisted of a HP 1090M liquid chromatograph equipped with a diode-array detector and a HP Kayak XM 600 ChemStation (Agilent Technologies, Waldbronn, Germany). Multiple wavelength monitoring was performed at 210,230,260,280,310,360, 435 and $500 \mathrm{~nm}$, and UV-visible spectra were measured from 200 to $600 \mathrm{~nm}$. A 10-ml aliquot of the fermentation broth was centrifuged, and the supernatant adjusted to $\mathrm{pH} 4$ and extracted with the same volume of EtOAc. After centrifugation, the organic layer was concentrated to dryness in vacuo and resuspended in $1 \mathrm{ml} \mathrm{MeOH}$. Here, $10 \mu \mathrm{l}$ aliquots of the samples were injected onto an HPLC column $(125 \times 4.6 \mathrm{~mm})$ fitted with a guard-column $(20 \times 4.6 \mathrm{~mm})$ filled with $5-\mu \mathrm{m}$ Nucleosil-100 C-18 (Maisch, Ammerbuch, Germany). The samples were analyzed by linear gradient elution using $0.1 \%$ ortho-phosphoric acid as solvent $\mathrm{A}$ and $\mathrm{MeCN}$ as solvent $\mathrm{B}$ at a flow rate of $2 \mathrm{ml} \mathrm{min}^{-1}$. The gradient was from 0 to $100 \%$ for solvent B in 15 min with a 2 -min hold at $100 \%$ for solvent B.

\section{Structural elucidation}

LC-MS experiments were performed on an Applied Biosystems QTrap 2000 (Applied Biosystems, Darmstadt, Germany) coupled to an Agilent 1100 HPLC system (Agilent). High-resolution ESI-FT-ICR mass spectra were recorded on an APEX II FTICR mass spectrometer (4.7 T, Bruker-Daltonics, Bremen, Germany) and NMR experiments on a DRX 500 NMR spectrometer (Bruker, Karlsruhe, Germany) equipped with a BBI probe head with z gradients.

\section{Biological activity}

Anti-microbial assays were performed as described earlier. ${ }^{26}$ The following strains were used: Staphylococcus epidermidis (DSM 20044), Pseudomonas syringae pvar. aptata (DSM 50252), Pseudomonas fluorescens (NCIMB 10586), Xanthomonas campestris (DSM 2405), Ralstonia solanacearum (DSM 9544) and Candida glabrata (DSM 6425).

Biofilm formation with Staphylococcus xylosus (DSM 20267) was analyzed by a crystal violet staining assay ${ }^{27}$ in $96-$-well microtiter plates with the following modifications: cells were cultivated at $37^{\circ} \mathrm{C}$ instead of $30^{\circ} \mathrm{C}$; the brain heart medium (BHI) was replaced by the trypticase soy yeast extract medium $\left(30 \mathrm{gl}^{-1}\right.$ Bacto tryptic soy broth and $3 \mathrm{gl}^{-1}$ yeast extract), the cell density at $600 \mathrm{~nm}$ of the initial bacterial suspension was 0.01 and $\mathrm{EtOH}$ was used instead of glacial acetic acid for solubilization of the incorporated dye.

The inhibitory action of caboxamycin (1) on the growth of tumor cells was tested according to NCI guidelines ${ }^{28}$ with the human tumor cell lines AGS (gastric adenocarcinoma), MCF7 (breast adenocarcinoma) and Hep G2 (hepatocellular carcinoma). Aliquots of cell suspensions $\left(5 \times 10^{3}\right.$ cells $)$ were placed in 96-well microtiter plates in $0.2 \mathrm{ml}$ culture medium (RPMI- 1640 with $10 \%$ fetal calf serum) and incubated in a humidified atmosphere of $5 \% \mathrm{CO}_{2}$ in air. After $24 \mathrm{~h}$ caboxamycin (1) $\left(0.1 \sim 10 \mu \mathrm{g} \mathrm{ml}^{-1}\right)$ and UK-1 (2) $\left(0.1 \sim 10 \mu \mathrm{g} \mathrm{ml}^{-1}\right)$ as positive control were added to the cells and the cells cultivated for additional $48 \mathrm{~h}$. The cell count was surveyed by protein determination with sulforhodamine B. From the resulting concentration-activity curves, the $\mathrm{GI}_{50}$ (concentration at which half of the cells were inhibited in their growth) and TGI (concentration at which a total inhibition of cell growth was observed) values were obtained.

Analysis of the effect of 1 on human recombinant cAMP-specific phosphodiesterase (PDE-4B2) was carried out with final concentrations of the substance of $488 \mu \mathrm{M}\left(125 \mu \mathrm{g} \mathrm{ml}^{-1}\right)$ in $50 \mathrm{~mm}$ Tris- $\mathrm{HCl}$ buffer ( $\left.\mathrm{pH} 7.5\right)$ containing $8.3 \mathrm{~mm}$ $\mathrm{MgCl}_{2}, 1.7 \mathrm{~mm}$ EGTA and $10 \mathrm{mU}$ recombinant human cAMP-specific PDE 4B2 (Merck Bioscience 524736-10U, Darmstadt, Germany) in a volume of $20 \mu \mathrm{l} \mathrm{per}$ well. The reaction was started with $20 \mu \mathrm{l}$ of $40 \mu \mathrm{M}$ cAMP (Sigma A9501, Taufkirchen, Germany) dissolved in $50 \mathrm{~mm}$ Tris- $\mathrm{HCl}$ ( $\mathrm{pH}$ 7.5) containing $8.3 \mathrm{mM} \mathrm{MgCl}_{2}$ and $1.7 \mathrm{~mm}$ EGTA. After an incubation period of $30 \mathrm{~min}$ at $30{ }^{\circ} \mathrm{C}$ the reaction was stopped and the AMP concentration was quantified with the PDELight HTS cAMP Phosphodiesterase Assay Kit (Lonza, LT07-600, Wuppertal, Germany) according to the instructions of the supplier. The luminescence was measured using the microtiter plate reader Infinite M200 (Tecan, Crailsheim, Germany) with $0.1 \mathrm{~s}$ integration time. For inhibition of the PDE, $100 \mu \mathrm{M}$ of Rolipram (4-[3-(Cyclopentyloxy)-4-methoxyphenyl]-2-pyrrolidinone) (Merck Bioscience Cat.No. 557330) were used as a positive control. The effect of 1 on PDE activity from bovine brain (a mixture of three isoforms PDE-2, PDE-4 and PDE-10) was tested accordingly. $10 \mathrm{~mm}$ Tris-HCl buffer (pH 7.4) was used containing $1 \mathrm{mU}(1 \mu \mathrm{l})$ of 3,5-cyclic-nucleotide-specific PDE from bovine brain $\left(\right.$ Sigma P9529) ${ }^{29}$ in a total volume of $20 \mu \mathrm{l}$, and the reaction was started with $20 \mu \mathrm{l}$ of $40 \mu \mathrm{m}$ cAMP (Sigma A9501) solution in $10 \mathrm{~mm}$ Tris-HCl pH 7.4.

\section{ACKNOWLEDGEMENTS}

This work was supported by Boehringer-Ingelheim Pharma GmbH (Biberach, Germany), the European Commission (project ACTINOGEN, 6th framework, Grant LSHM-CT-2004-005224). We thank the crew of the RRS Charles Darwin for collecting deep-sea samples and Dr DG Masson (National Oceanography Centre, Southampton, UK) for access to the sediment cores, Mr G Grewe, Universität Tübingen for assistance in fermentations, Mrs A Erhard, IFMGEOMAR for technical support and Agilent Technologies (Waldbronn, Germany) for HPLC-software support.

1 Jensen, P. R., Mincer, T. C., Williams, P. G. \& Fenical, W. Marine actinomycete diversity and natural product discovery. Antonie van Leeuwenhoek. 87, 43-48 (2005).

2 Fiedler, H.-P. et al. Marine actinomycetes as a source of novel secondary metabolites. Antonie van Leeuwenhoek. 87, 37-42 (2005).

3 Fenical, W. \& Jensen, P. R. Developing a new resource for drug discovery: marine actinomycete bacteria. Nature Chem. Biol. 2, 666-673 (2006).

4 Lam, K. S. Discovery of novel metabolites from marine actinomycetes. Curr Opin Microbiol 9, 245-251 (2006).

5 Bull, A. T. \& Stach, J. E. M. Marine actinobacteria: new opportunities for natural product search and discovery. Trends Microbiol. 15, 491-499 (2007).

6 Fiedler, H.-P. Biosynthetic capacities of actinomycetes. 1. Screening for novel secondary metabolites by HPLC and UV-visible absorbance libraries. Nat. Prod. Lett. 2, 119-128 (1993).

7 Sommer, P. S. M. et al. Nataxazole, a new benzoxazole derivative with antitumor activity produced by Streptomyces sp. Tü 6176. J. Antibiot. 61, 683-686 (2008).

8 Ueki, M. et al. UK-1, a novel cytotoxic metabolite from Streptomyces sp. 517-02. I. Taxonomy, fermentation, isolation, physico-chemical and biological properties. J. Antibiot. 46, 1089-1094 (1993).

9 Sato, S. et al. AJI9561, a new cytotoxic benzoxazole derivative produced by Streptomyces sp. J. Antibiot. 54, 102-104 (2001).

10 Manfio, G. P., Zakrezewska-Czerwinska, J., Atalan, E. \& Goodfellow, M. Towards minimal standards for the description of Streptomyces species. Bioteckhnologia 7-8, 242-253 (1995).

11 Stach, J. E. M. et al. Statistical approaches for estimating actinobacterial diversity in marine sediments. Appl. Environm. Microbiol. 69, 6189-6200 (2003).

12 Shibata, K., Kashiwada, M., Ueki, M. \& Taniguchi, M. UK-1, a novel cytotoxic metabolite from Streptomyces sp. 517-02. II. Structural elucidation. J. Antibiot. 46, 1095-1100 (1993).

13 Ueki, M. \& Taniguchi, M. UK-1, a novel cytotoxic metabolite from Streptomyces sp. 517-02. III. Antibacterial action of demethyl UK-1. J. Antibiot. 50, 788-790 (1997).

14 Ueki, M., Shibata, K. \& Taniguchi, M. UK-1, a novel cytotoxic metabolite from Streptomyces sp. 517-02. IV. Antifungal action of methyl UK-1. J. Antibiot. 51, 883-885 (1998).

15 Kumar, D., Jacob, M. R., Reynolds, M. B. \& Kerwin, S. M. Synthesis and evaluation of anticancer benzoxazoles and benzimidazoles related to UK-1. Bioorg. Med. Chem. 10, 3997-4004 (2002).

16 Wang, B. B., Maghami, N., Goodlin, V. L. \& Smith, P. J. Critical structural motif for the catalytic inhibition of human topoisomerase II by UK-1 and analogs. Bioorg. Med. Chem. Lett. 14, 3221-3226 (2004).

17 Huang, S.-T., Hsei, I.-J. \& Chen, C. Synthesis and anticancer evaluation of bis(benzimidazoles), bis(benzoxazoles), and benzothiazoles. Bioorg. Med. Chem. 14, 6106-6119 (2006).

18 Reynolds, M. B., DeLuca, M. R. \& Kerwin, S. M. The novel bis(benzoxazole) cytotoxic natural product UK-1 is a magnesium ion-dependent DNA binding agent and inhibitor of human topoisomerase II. Bioorg. Chem. 27, 326-337 (1999).

19 Fairfax, D. J. \& Yang, Z. Benzoxazolecarboxamides for treating CINV and IBS-D and their preparation and pharmaceutical compositions. US Pat. Appl. 20,060,183,769, August 17 (2006).

20 Michel, K. H., Boeck, L. D., Hoehn, M. M., Jones, N. D. \& Chaney, M. O. The discovery, fermentation, isolation, and structure of antibiotic A33853 and its tetraacetyl derivative. J. Antibiot. 37, 441-445 (1984).

21 Giembycz, M. Phosphodiesterase-4 inhibitors and the treatment of asthma. Drugs 59, 192-212 (2000).

22 Houslay, M., Schafer, P. \& Zhang, K. Phosphodiesterase-4 as a therapeutic target. Drug Discov. Today 11, 1503-1519 (2005).

23 Manning, C. et al. Suppression of human inflammatory cell function by subtypeselective PDE4 inhibitors correlates with inhibition of PDE4A and PDE4B. Brit. J. Pharmacol. 128, 1393-1398 (1999).

24 Williams, S. T., Goodfellow, M. \& Alderson, G. Genus Streptomyces Waksman and Henrici 1943, 339AL. In: S. T. Williams et al. (eds). Bergey's Manual of Systematic Bacteriology, Vol. 4. Williams \& Wilkins: Baltimore. pp 2452-2492 (1989). 
$25 \mathrm{Xu}, \mathrm{C}$. et al. Neutrotolerant acidophilic Streptomyces species isolated from acidic soils in China: Streptomyces guanduensis sp. nov., Streptomyces paucisporus sp. nov., Streptomyces rubidus sp. nov. and Streptomyces yanglinensis sp. nov. Int. J. Syst. Evol. Microbiol. 56, 1109-1115 (2006).

26 Lang, G., Wiese, J., Schmaljohann, R. \& Imhoff, J. F. New pentaenes from the spongederived marine fungus Penicillium rugulosum: structure determination and biosynthetic studies. Tetrahedron 63, 11844-11849 (2007).
27 Chavant, P., Gaillard-Martinie, B., Talon, R., Hebraud, M. \& Bernardi, T. A new device for rapid evaluation of biofilm formation potential by bacteria. J. Microbiol. Methods 68, 605-612 (2007).

28 Grever, M. R., Shepartz, S. A. \& Chabner, B. A. The National Cancer Institute: cancer drug discovery and development program. Semin. Oncol. 19, 622-638 (1992).

29 Morill, M., Thompson, S. \& Stellwagen, E. Purification of a cyclic nucleotide phosphodiesterase from bovine brain using blue dextran-sepharose chromatography. J. Biol. Chem. 254, 4371-4374 (1979). 